D.O.I.: $10.3895 / \mathrm{S} 1808-04482007000400001$

\title{
COMPETITIVIDADE SISTÊMICA: UM MODELO DE ANÁLISE DE CENÁRIOS PARA GESTÃO DE EMPRESAS
}

\section{SYSTEMIC COMPETITIVENESS: A MODEL OF ANALYSIS OF SCENES FOR COMPANIES MANAGEMENT}

\author{
Antonio Carlos Dantas Cabral ${ }^{1}$; Afonso Carlos Corrêa Fleury ${ }^{2}$ \\ ${ }^{1}$ Instituto Mauá de Tecnologia - IMT - São Caetano do Sul, SP - Brasil acabral@maua.br \\ ${ }^{2}$ Universidade de São Paulo - USP - São Paulo, SP - Brasil acfleury@usp.br
}

\begin{abstract}
Resumo
Este trabalho teve como objetivo desenvolver e validar modelo de gestão de empresas que atuam em cadeias produtivas caracterizadas pela turbulência e pela pouca disponibilidade de indicadores, adaptando conceitos da Teoria das Restrições (TTOC). O modelo, denominado Competitividade Sistêmica, que permite coletar e interpretar dados, desenhar cenários, alicerçar decisões e buscar a vantagem competitiva, foi desenvolvido com base no pensamento sistêmico, nas estratégias de diferenciação e nas de negociação. Os resultados obtidos em 70 entrevistas na Cadeia Produtiva de Alimentos validaram a sua aplicabilidade e permitiram identificar três pontos críticos a considerar na elaboração das estratégias: ênfase excessiva em custos; falta de visão sistêmica; e conhecimento e competências não desenvolvidos de forma adequada. Ele pode ser também usado em cadeias estáveis, como leitura adicional, para complementar o cenário no qual atuam.
\end{abstract}

Palavras-chave: cadeias produtivas, vantagem competitiva, competitividade sistêmica, teoria das restrições.

\section{Introdução}

Este trabalho teve como objetivo desenvolver e validar modelo de gestão de empresas que atuam em cadeias produtivas caracterizadas pela turbulência e pela pouca disponibilidade de indicadores adaptando conceitos da Teoria das Restrições (TOC).

A TOC é uma metodologia de gerenciamento de sistemas produtivos que trabalham com um objetivo específico denominado meta. Esses sistemas são comparados a uma corrente na qual todos os seus departamentos ou agentes, os elos, trabalham juntos para dar lucro aos acionistas, o que, na analogia adotada, significa transmitir força. Tal qual correntes, o sistema tem um elo fraco, chamado de restrição, que limita a sua capacidade ou representa uma dificuldade para atingir o objetivo. Para identificar essas restrições e melhorar continuamente o desempenho organizacional, 
Goldratt; Cox (1992) criaram o Processo de Raciocínio Lógico que, em essência, força as pessoas, dirigentes ou não, a deduzirem suas soluções (Goldratt, 1990) ensinando-as a pensar (Calia, 2001 e Calia, 2002).

A TOC oferece um roteiro estruturado, simultaneamente lógico e criativo, objetivando desenhar cenários, formular estratégias e alicerçar soluções para os problemas gerenciais do cotidiano dos sistemas produtivos. Para tanto, baseia-se na definição clara do contorno o sistema e da sua meta, e em indicadores reconhecidos para aferir o desempenho.

Quando o sistema é turbulento, em que a governança não é evidente ou está sendo transferida para outro agente, é essencial dispor de um roteiro para se "locomover" entre os agentes e garimpar dados e informações e compor a base que alicerce as decisões. Nessa cirscuntância, os indicadores habituais podem não ser suficientes porque retratam apenas parte da realidade, fato que reduz a confiabilidade. Esse roteiro para coletar e interpretar dados, desenhar cenários, alicerçar decisões e buscar a vantagem competitiva é o modelo de gestão proposto neste trabalho.

A Cadeia Produtiva de Alimentos (CPA) pode ser considerada um sistema turbulento, visto que a governança, seguindo os conceitos de Gereffi, (1994), passa rapidamente de "producer driven" para "buyer driven". Por essas razões, foi escolhida como o objeto de estudo.

\section{A construção do modelo}

O principal ponto da Teoria das Restrições Goldratt (1990), citado anteriormente nesse texto, é entender empresas e cadeias produtivas como sistemas integrados que têm como objetivo, ou "meta", ganhar dinheiro adicionando o valor econômico que permitirá a sua sobrevivência.

A expressão adicionar (ou agregar) valor econômico é fundamentada no conceito EVA (em inglês Economic Value Added), criado por Stern; Shiely; Ross (2000). Assim agindo, fortalecem-se os recursos materiais e humanos, aumenta-se a competitividade e garante-se a sobrevivência.

Dettmer (2000) relaciona os três fatores que considera os mais importantes para se atingir a meta: a estratégia de diferenciação relação aos concorrentes, estratégias de negociação bem delineadas e os funcionários satisfeitos. Os dois primeiros foram objeto de publicações de Porter (1992) e Porter (1986). Trout (2000) também cita a diferenciação como o fator crítico de sucesso. O terceiro faz parte da Visão Sistêmica ou Pensamento Sistêmico, ricamente detalhado por Senge (1990) e Senge et al (1997).

Esses conceitos são o ponto de partida do modelo que se constrói nesse trabalho. Eles são representados na Figura 1. Sua leitura, a partir da esquerda, no sentido contrário ao das flechas, é a seguinte: "para atingir a meta é preciso ter estratégias de negociação bem definidas e estratégias de 
diferenciação bem definidas e visão sistêmica”. Cada uma dessas condições é necessária, e, em conjunto, as três são suficientes para atingir a meta.

Figura 1: Ponto de partida do modelo proposto

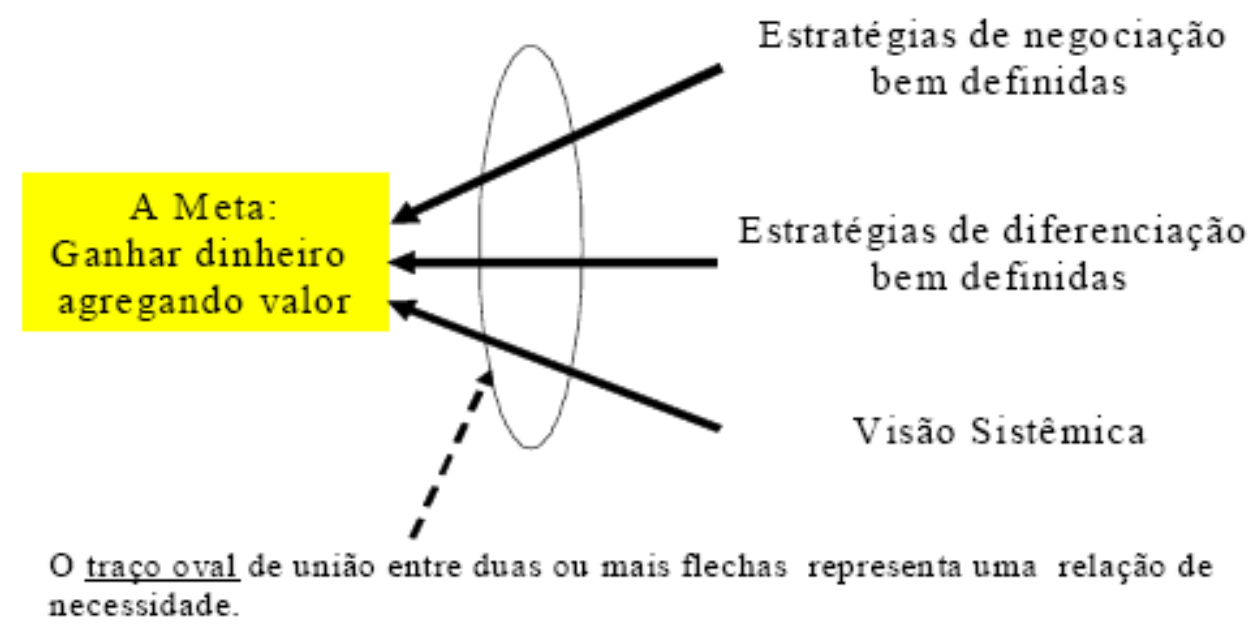

A TOC permite sejam incorporados outros conceitos para auxiliar a adequada interpretação dos fatos que compõe a realidade. Assim foi feito na Figura 1, para as estratégias de diferenciação e para a visão sistêmica, que foram exploradas até o ponto considerado ideal pelos autores. As estratégias de negociação bem definidas, aspecto fundamental da TOC, são específicas para cada empresa e cada cadeia produtiva e, explorá-las, significa penetrar num mundo muito particular, repleto de nuances que fatalmente comprometeriam o foco que se pretendeu dar a esse trabalho. Em última análise, segundo Calia (2002), as estratégias de negociação devem ser norteadas pela preocupação em preparar e apresentar propostas éticas irrecusáveis aos clientes.

A Figura 2 consolida todos os conceitos agregados ao modelo denominado pelos autores como "competitividade sistêmica", porque pressupõe que empresas e cadeias produtivas são sistemas que devem ser competitivos para sobreviver. 
Figura 2: Modelo "Competitividade Sistêmica"

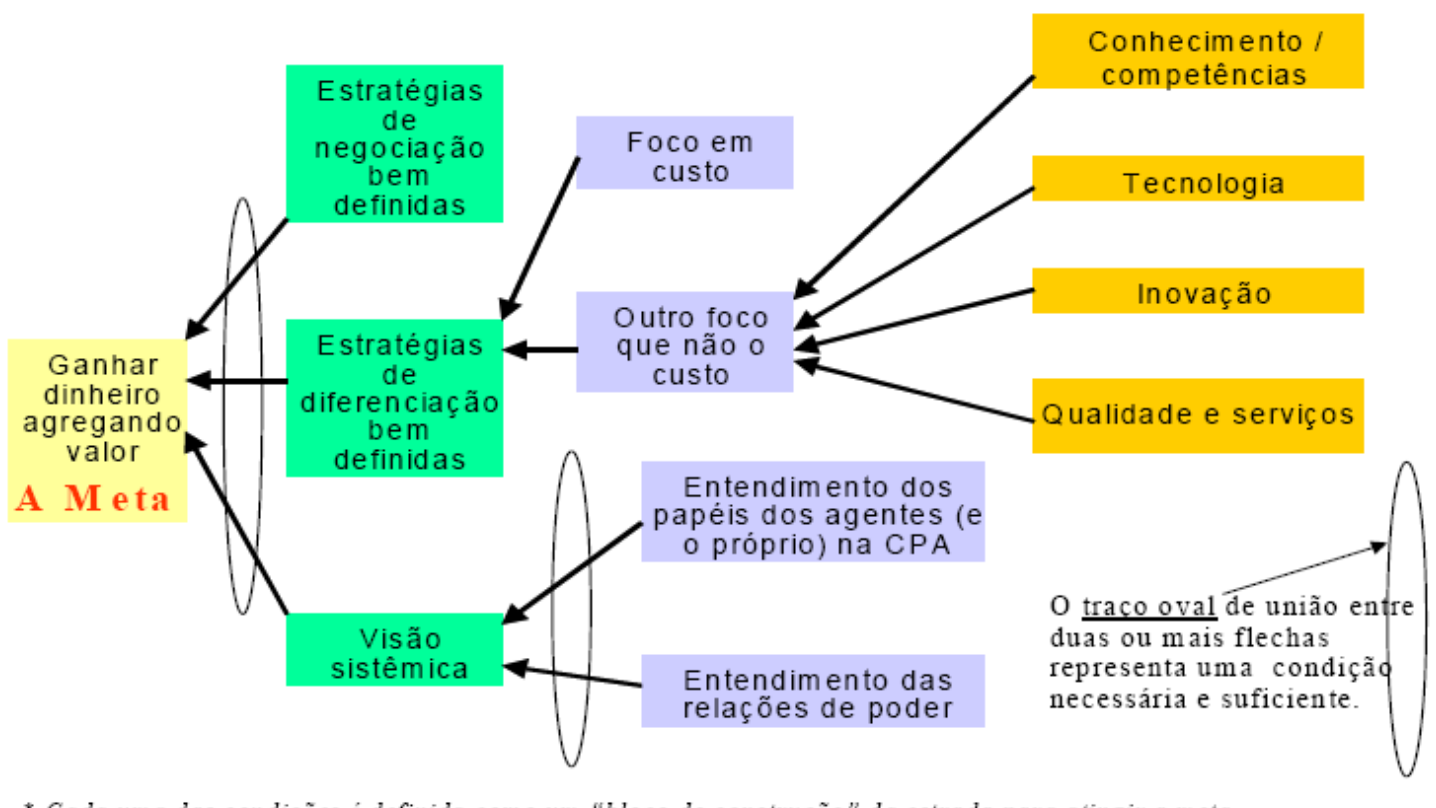

* Cada uma das condições é definida como um "bloco de construção" da estrada para atingir a meta.

Ao considerar a visão sistêmica, pode-se afirmar que: "para se ter visão sistêmica é necessário o entendimento dos papéis (e o próprio) e o entendimento das relações entre os agentes, especialmente as de poder". A Figura 3 posiciona cada uma das disciplinas enunciadas por Senge (1990) de modo a permitir a melhor compreensão do modelo. É importante compreender que Domínio Pessoal e Modelos Mentais relacionam-se aos indivíduos e que Aprendizagem em Time e dos Objetivos Comuns, dizem respeito aos departamentos, às empresas ou mesmo à própria cadeia produtiva.

Figura 3: As disciplinas do Pensamento Sistêmico (Senge, 1990), o entendimento do papel dos agentes e das relações de poder.

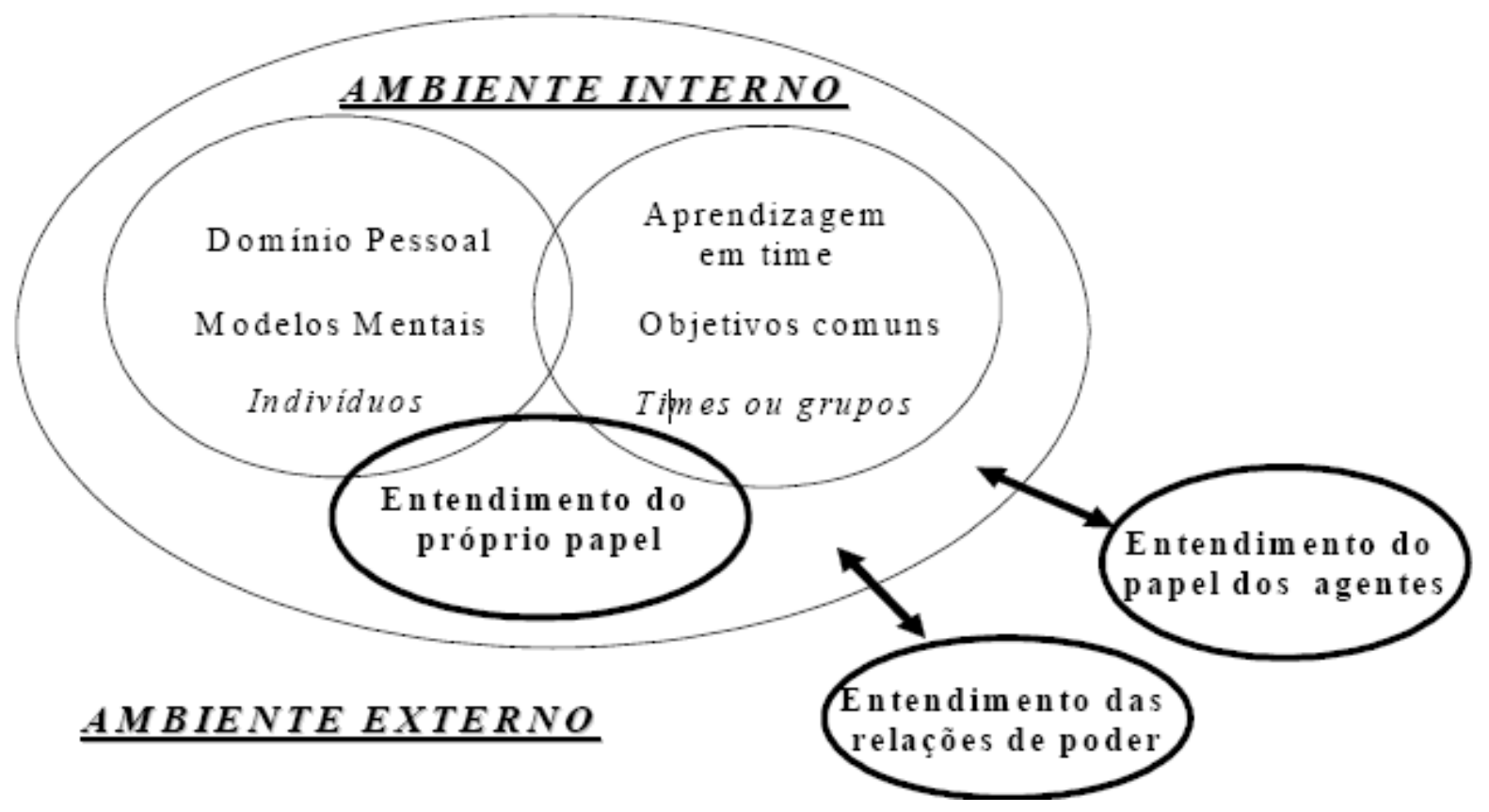


Voltando à Figura 2, observa-se que as estratégias de diferenciação são analisadas nos termos descritos por Porter, (1986), Porter (1992) e Trout, (2000). Ao resumi-los na linguagem TOC, foram renomeadas as denominações dadas por Porter (1992), como foco em custo e outro foco que não o custo, referindo, respectivamente à liderança em custo e à diferenciação. Pode-se então afirmar que: "para ter estratégias de diferenciação bem definidas é preciso ter foco em custo ou outro foco que não o custo". Os conceitos a seguir citados em negrito embasam o "outro foco que não o custo":

- Conhecimento, segundo Ferreira (1987), no Pequeno Dicionário da Língua Portuguesa, é o ato ou efeito de conhecer, cabedal científico, consciência de si próprio. Competência, segundo Fleury; Fleury (2000) é “um saber agir responsável e reconhecido, que implica mobilizar, integrar, transferir conhecimentos, recursos, habilidades, que agreguem valor econômico à organização e valor social ao indivíduo";

- Uma empresa tem vantagem competitiva por tecnologia quando consegue afetar positivamente a posição de custo ou de diferenciação, ou melhor dizendo, os condutores de custo ou de diferenciação;

- A inovação foi analisada multidisciplinarmente seguindo as três dimensões apresentadas por Tidd; Bessant; Pavitt (1997): a competência para transformar tecnologia em produtos e serviços; o entendimento sistêmico das atividades de Pesquisa e Desenvolvimento; o fortalecimento das relações com os fornecedores e consumidores ou clientes. A velocidade da inovação é a vantagem competitiva a ser explorada;

- Trout (2000, p.37) afirma que "a qualidade e os serviços não entendidos pelos clientes como uma diferença a ser valorizada. Conhecer e apreciar o cliente é uma obrigação". Esses conceitos têm a seguinte leitura na Figura 2: "para ter outro foco que não o custo é necessário ter foco em conhecimento / competência ou foco em tecnologia ou foco em inovação ou foco em qualidade e serviços" (apenas uma das duas condições é necessária para validar a relação).

\section{Metodologia}

Para validar o modelo elaborado, foram selecionadas empresas fabricantes e usuárias de três tipos de embalagens - garrafas PET, embalagens cartonadas e filmes flexíveis, supermercados e agências de design de embalagem, compondo um amplo espectro de pontos de vista e de estilos gerenciais.

Os dados primários foram obtidos pelo próprio pesquisador através de entrevistas com 70 agentes da CPA, em duas etapas, utilizando questionário estruturado e não disfarçado. Na primeira, 
os agentes identificaram problemas e situações que foram condensados em frases que representassem "Efeitos Indesejáveis" - EI's. Esses EI's podem ser comparados a sintomas ou indícios de patologias empresariais. Na segunda etapa, os EI's foram validados em breves contatos com os entrevistados.

Em seguida, os EI's foram agrupados e distribuídos graficamente no modelo “competitividade sistêmica" mostrado na Figura 2. Desenhou-se dessa forma o cenário atua, que, na linguagem TOC, é denominado Árvore da Realidade Atual, ou simplesmente ARA, que deve ser entendida como um retrato do momento presente.

A partir da ARA, a empresa pode planejar suas ações com o intuito de reduzir EI's num ponto específico ou então agir mais amplamente, reduzindo o número total de EI's. Ao cenário objetivo dessas ações, a TOC dá o nome de Árvore da Realidade Futura, ou ARF.

Evidencia-se assim o uso dos EI's como um indicador TOC de gerenciamento específico para ambientes em que os indicadores convencionais não estejam disponíveis ou não tenham a requerida confiabilidade.

\section{Resultados e Discussões}

Foram selecionados 100 EI's, citados, ao todo, 1025 vezes na pesquisa, e distribuídos no modelo. Alguns dos mais representativos são relacionados a seguir:

- Falta de conhecimento técnico em parte dos vendedores de embalagem;

- A visão sistêmica não está difundida entre todas as indústrias de embalagem;

- Os vendedores de embalagem são acomodados e precisam ser constantemente ameaçados para reagirem;

- As indústrias de embalagem têm informações mas não geram conhecimento. Não investem em conhecimento;

- As expectativas de atendimento diferenciado não são atendidas pelos vendedores das indústrias de embalagem;

- O papel do custo nas relações comerciais é exagerado;

- A pressão por preços menores à jusante inibe investimentos em conhecimento nas indústrias de embalagem;

- As grandes indústrias de alimentos têm o poder na negociação;

- Falta de conhecimento técnico dos compradores de embalagem;

A Figura 4 mostra a sua disposição na ARA, enfatizando aquelas que foram consideradas as suas principais fontes. A título de exemplo, 198 citações (19\% do total) foram enquadradas como foco em custo. Sua análise critérios permite as considerações seguir apresentadas. 


\section{Estratégias de negociação ( 223 citações)}

Foram identificados 26 EI's que foram citados pelos 70 agentes. Com base nelas, pode-se inferir que as indústrias de alimentos concentram-se de tal forma na otimização de seus custos que deixam de conectar os fins (a lucratividade e a posição da empresa no mercado) e os meios (os elementos criativos que possibilitem obter e manter tal posição).

Considerando os fatores de sucesso nos relacionamentos que Kanter (1994) desenvolveu, foram observados: comprometimento da "importância", porque os relacionamentos não estão ajustados aos objetivos estratégicos; baixa "integração", porque não estão sendo desenvolvidas a contento novas maneiras de se relacionar e de negociar; e um esforço muito grande para aumentar a “interdependência", sinergizando atividades e serviços, ainda que de forma embrionária. Os agentes em questão têm "excelência individual", pois têm como contribuir no relacionamento. Além deles, foram observados: falta de transparência e de confiança mútua, arrogância, o efeito "devastador" dos leilões eletrônicos, as constantes alterações nas programações de compra e a falta de criatividade no encaminhamento das soluções para os problemas cotidianos. Percebe-se aí uma miríade de oportunidades a explorar.

Figura 4: Árvore da Realidade Atual mostrando os agrupamentos de EI's e suas fontes

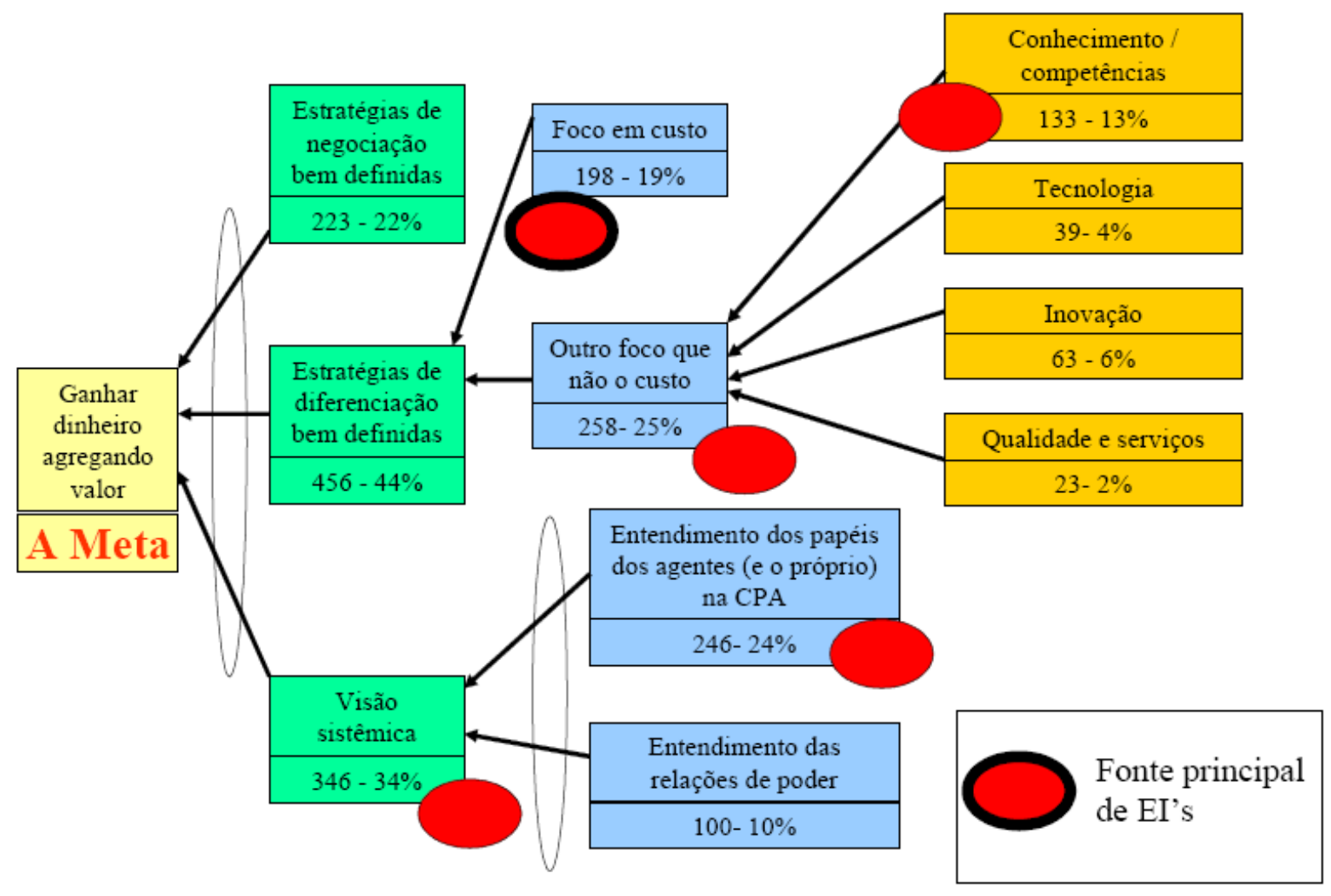

\section{Estratégias de diferenciação - foco em custo (456 citações)}

Os 14 EI's relacionados com o custo representam 19\% de todas as citações feitas pelos entrevistados. Todos eles têm, como ponto comum, a grande preocupação com a própria sobrevivência das indústrias. O custo tornou-se o centro de todas as atenções no cotidiano 
empresarial. Como conseqüência, são tomadas decisões de curto prazo, sem a necessária visão sistêmica, gerando um círculo vicioso que pode perpetuar a não geração de valor.

Observou-se durante as entrevistas, que não existem soluções percebidas para eliminar esta questão. Somente um trabalho paciente, poderá equilibrar a distribuição do valor gerado nas cadeias produtivas. O primeiro passo na busca desse equilíbrio é construir a visão sistêmica para, a partir dela, identificar quais estratégias, deverão ser utilizadas. O pensamento sistêmico, se adotado em toda a organização, pode ser um centro gerador de Efeitos Desejáveis.

\section{Estratégias de diferenciação - outro foco que não o custo (258 citações)}

A segunda das "estratégias de diferenciação bem definidas" do modelo "Competitividade Sistêmica” da Figura 4 é "outro foco que não o custo".

Foram agrupados 13EI's sob o título Conhecimento / Competências. A falta de conhecimento técnico é o epicentro das tumultuadas negociações de embalagem. As competências dos profissionais para conduzir os seus negócios, medida pela efetividade da venda e da compra, em termos do "saber agir" e do "saber assumir responsabilidades" apresentados por Fleury; Fleury (2000), não é posta em dúvida. O que se questiona é o "saber aprender", o "saber mobilizar", enfim, qual o tipo de atitude possibilitará atingir a meta.

Em suma, há a percepção que algo precisa ser feito para transformar este momento de uma simples transação comercial num ponto de encontro entre profissionais gabaritados, trabalhando para adicionar valor econômico às empresas. Surge aí o conceito de "negociação inteligente" que é o encontro entre o "vendedor solucionador de problemas" com o "comprador catalisador de soluções".

Sob o título Tecnologia foram colocados 6 EI's (39 citações). Os agentes esperam que, com o desenvolvimento de tecnologia, as empresas possam se diferenciar no mercado e melhorar seu desempenho financeiro, ou, atingir a meta de forma sustentada. Com esse objetivo, várias indústrias de embalagem recorreram a compras de equipamentos de última geração. No entanto, infelizmente, parte delas não internalizou a tecnologia agregada a essas máquinas e se fragilizam frente à concorrência. Já uma outra parte construiu conhecimento e assim agindo, pôde destacar-se no ambiente competitivo sem comprometer a vantagem em custo.

Sob Inovação foram colocados 7 EI's (63 citações) analisados com base nos conceitos apresentados por Tidd (1997). Inovar com inteligência é, para uns, encontrar um nicho de mercado que valorize e remunere, adequadamente, o seu produto ou a sua embalagem ou ainda o serviço que presta. É possível inovar com inteligência utilizando o Projeto Integrado (Cabral, 2000), que tem a visão sistêmica como seu alicerce. O ponto central desses EI's é, usando palavras dos agentes, “a falta de tempo para inovação na indústria de alimentos". 
O agrupamento Qualidade e Serviços foi o que teve a menor quantidade de citações (23). Duas interpretações são possíveis para o fato: não se trata de significativa "fonte de EI's" e foram desenvolvidos mecanismos que resolvem os problemas à medida que surgem, ou os agentes não percebem a qualidade e os serviços, como vantagem competitiva .

O observador atento identificará aí uma excelente oportunidade de diferenciação visto que o mercado parece estar acomodado, ou preocupado apenas com a redução de custos, e se a prestação de serviço for desenhada univocamente para um determinado usuário, poderá significar uma vantagem competitiva e encurtar a distância até a meta.

\section{Visão sistêmica (346 citações)}

Os EI's relacionados com a o entendimento do papel dos agentes na CPA citados 246 vezes pelos entrevistados. Ao explorar melhor o tema, foi possível detectar que a compreensão que eles têm do próprio papel na CPA é restrita à eficiência operacional, à eficácia no atendimento ao cliente e às conseqüências das políticas dos fornecedores. Esse entendimento restringe-se, portanto, ao micro-sistema composto pela própria empresa e pelos vizinhos imediatamente à montante e à jusante. Em razão dos modelos mentais adotados por eles, poucos se importam em estender essa visão além dessa fronteira restrita que estabelecem.

Os EI's relacionados com o entendimento das relações de poder foram citados 100 vezes pelos entrevistados. Constatou-se que a pressão por menores preços exercida pelos supermercados nos departamentos de compras das indústrias de alimentos é repassada diretamente às indústrias de embalagem. Estas, por sua vez, como não vêm nos compradores a porta de entrada que necessitam para, na linguagem de Senge (1990), alavancar uma solução exeqüível, ou, nos termos de Goldratt (1990) e Calia (2001), apresentar uma "proposta irrecusável”, concentram seus esforços na permanente redução de custos.

Está desenhado o cenário atual, a ARA, base para as decisões estratégicas das empresas.

\section{O cenário futuro}

A ARA permite identificar três pontos críticos a considerar na elaboração das estratégias: ênfase excessiva em custos; falta de visão sistêmica; e conhecimento e competências não desenvolvidos de forma adequada.

Como dito anteriormente, a partir dela, a empresa pode planejar suas ações com o intuito de reduzir EI's num ponto específico, por exemplo, reduzir de 133 para 20, em 1 ano, as citações de EI's em Competências, como mostrado na Figura 5. Outra possibilidade, mais ampla, é reduzir o número total de EI's de 100 para 50 em 3 anos, considerando que o modelo pressupõe, como situação ideal, a distribuição homogênea de poucos EI's, que sempre existirão. 
Figura 5: Árvore da Realidade Futura evidenciando objetivo a atingir em Conhecimento e Competências

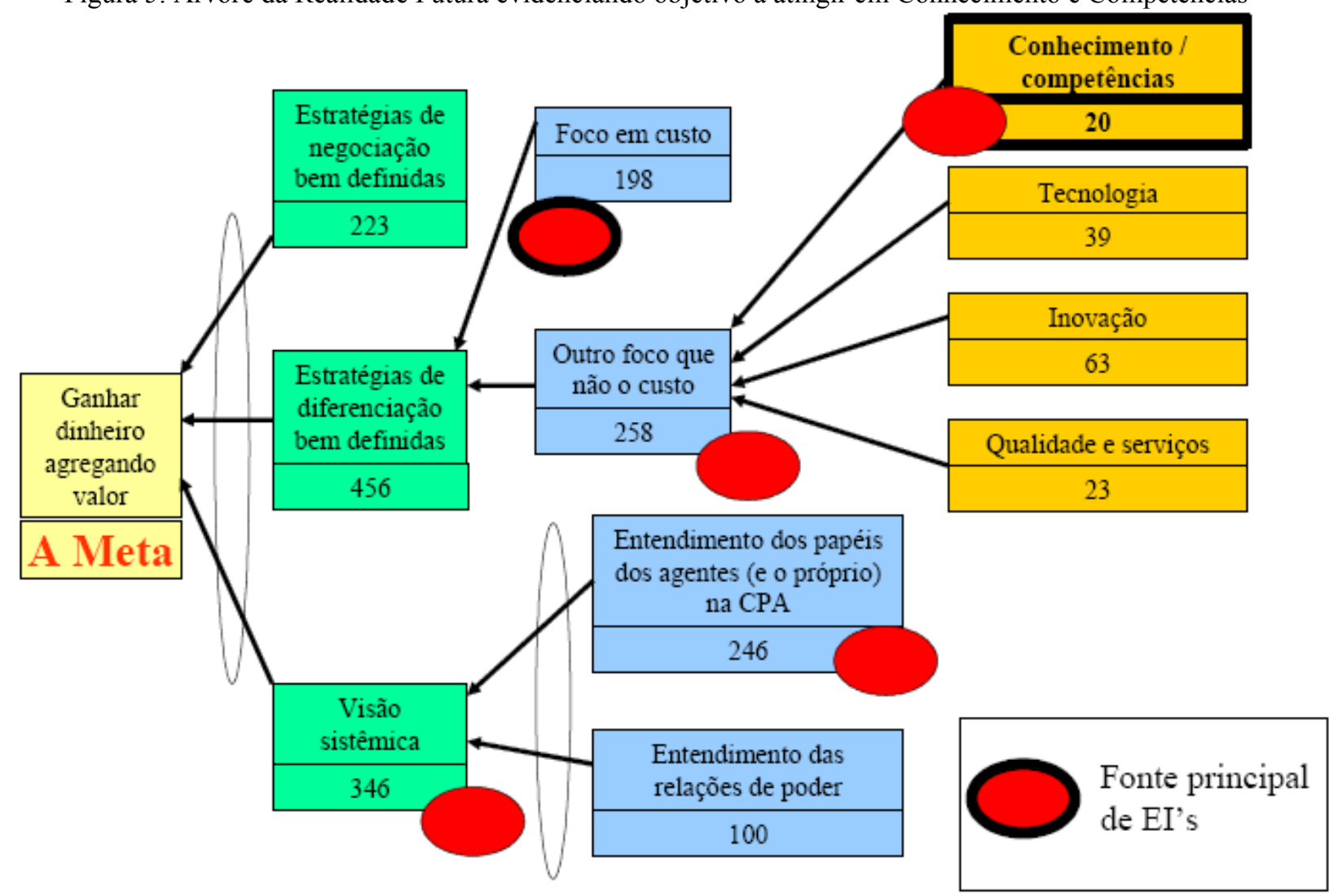

Como se vê, o modelo permite visualizar, de forma inquestionável qual o objetivo a atingir.

\section{Considerações sobre a metodologia desenvolvida}

A metodologia desenvolvida tem os seguintes pontos fortes: força os agentes a estabelecer claramente a meta das empresas; permite estudo de cadeias turbulentas em que os indicadores podem não estar disponíveis ou não serem confiáveis; guia a análise criteriosa dos EI's via ARA; desenha a situação ideal ou objetivos a atingir na ÁRF; cria um indicador simples de avaliação de desempenho que é o número de EI’s.

Por outro lado, ela tem as seguintes limitações: é muito grande o tempo despendido para analisar a cadeia produtiva; exige disponibilidade e predisposição dos agentes em permitir vários escrutínios ou validações; não tem suficiente poder para despertar a disposição dos agentes para divulgar indicadores numéricos.

\section{Conclusões}

Os objetivos propostos foram plenamente atingidos: foi desenvolvido e validado o modelo de gestão de empresas intitulado "Competitividade Sistêmica" que atuam em cadeias produtivas caracterizadas pela turbulência e pela pouca disponibilidade de indicadores, adaptando conceitos da 
Teoria das Restrições (TOC). Ele pode ser também usado em cadeias estáveis, como leitura adicional, para complementar o cenário no qual atuam.

O modelo permite analisar objetivamente qualquer sistema bem definido, oferecendo alternativas lógicas de melhoria contínua, reunindo os pensamentos linear, típico dos profissionais das ciências exatas, e o lateral, representado pela intuição.

\begin{abstract}
This study aimed to develop and validate the model of management of companies that operate in production chains characterized by the turbulence and the low availability of indicators, adapting concepts of the Theory of Constraints (TTOC). The model, called Systemic Competitiveness, which allows to collect and to interpret data, to design scenarios, to support decisions and to seek competitive advantage, had been developed based on the systemic thought, the strategies of differentiation and negotiation. The results found in 70 interviews in the production of food chain validated its applicability and identified three points critical to consider in developing strategies: excessive emphasis on costs, lack of systemic vision, and knowledge and skills not developed adequately. It can also be used in stable chains, as additional reading, to complement the scene where they act.

Keywords: Productive chains, competitive advantage, systemic competitiveness, theory of constraints.
\end{abstract}

\title{
Referências
}

CABRAL, A. C. D. Manual de desenvolvimento de embalagens laminadas flexíveis. São Paulo: ABRAFLEX Associação Brasileira das Embalagens Laminadas Flexíveis, 2000b. 55p.

CALIA, C. Projeto holístico da teoria das restrições. Programa Jonah parte 1. São Paulo, Instituto Mauá de Tecnologia, dez. 2001 / Curso de 40 horas ministrado pelo Avraham Y. Goldratt Institute do Brasil, São Paulo, 2001.

CALIA, C. Projeto holístico da Teoria das Restrições. Programa Jonah parte 2. São Paulo, Instituto Mauá de Tecnologia, jan. 2002 / Curso de 40 horas ministrado pelo Avraham Y. Goldratt Institute do Brasil, São Paulo, 2002.

DETTMER, H. W. Teoria das restrições: uma introdução com Bill Dettmer. São Paulo, Banas, 8 maio $2000 . /$ Seminário patrocinado pela Editora Banas, São Paulo, 2000.

FERREIRA, A. B. H. Pequeno dicionário da língua portuguesa. Rio de Janeiro: Civilização Brasileira, 1987. 1300p.

FLEURY, A. \& FLEURY, M. T. L. Capacitação competitiva da indústria de transformação de plásticos. São Paulo: USP, 1998. 62p. (Relatório preparado para o BNDES).

GEREFFI, G. The organization of buyer-drive global commodity chains: how U.S. retailers shape overseas production networks. In: GEREFFI, G.; KORZENIEWICZ, M. Commodity chains and global capitalism. Westport: Greenwood Press, 1994. p.95-122.

GOLDRATT, E. M. What is this thing called theory of constraints and how should it be implemented? EUA: North River Press, 1990. 162p.

GOLDRATT, E. M. \& COX, J. A meta. São Paulo: Educator / IMAM, 1992. 262p.

KANTER, R. M. Collaborative advantage: the art of alliances. Harvard, Harvard Business Review, n.4, p.96 - 112 , Jul. /ago. 1994.

PORTER, M. E. Estratégia competitiva. Trad. Elizabeth Maria de Pinho Braga. São Paulo: Campus, 1986. 362p. 
SENGE, P. A quinta disciplina. 14.ed. Trad. Regina Amarante. São Paulo: Best Seller, 1990. 352 p.

SENGE, P. \& KLEINER, A. \& ROBERTS, C. \& ROSS, E. \& SMITH, B. A quinta disciplina: caderno de campo.

Trad. Antônio Romero Maia da Silva. São Paulo: Qualitymark, 1997. 544p.

STERN; J. M. \& SHIELY, J. S. \& ROSS, I. The EVA challenge: implementing value added change in the organizations. New York: John Willey \& Sons, 2000. 250p.

TIDD, J. \& BESSANT, J. \& PAVITT, K. Managing innovation. West Sussex: John Willey \& Sons, 1997. 375p.

TROUT, J. Diferenciar ou morrer. Trad. Eduardo Lassere. São Paulo: Futura, 2000. 237p.

\section{Dados dos autores:}

Nome completo: Antonio Carlos Dantas Cabral

Filiação institucional: Instituto Mauá de Tecnologia, Escola de Engenharia Mauá

Departamento: Engenharia Química.

Função: Professor Titular

Endereço completo: Instituto Mauá de Tecnologia, Escola de Engenharia Mauá, Departamento de

Engenharia Química. Praça Mauá 1, São Caetano do Sul, SP - Brasil

Telefones: (11) 4239-3401 Fax: (11) 4239-3041

E-mail: acabral@maua.br

Nome completo: Afonso Carlos Corrêa Fleury

Filiação institucional: Universidade de São Paulo, Escola Politécnica

Departamento: Engenharia de Produção

Função: Professor Titular

Endereço completo: Universidade de São Paulo, Escola Politécnica.

Av. Prof. Almeida Prado, 531, 2o. Andar, Butantã

CEP: 05508-900 - São Paulo, SP - Brasil

Telefones: (11) 3091-5363 Ramal: 382 Fax: (11) 3091-5399

E-mail: acfleury@usp.br 